\title{
Comparison of Ultimate Capacities of RC Chimney Sections under Wind Loading
}

\author{
Megha Bhatt* and Sandip Vasanwala \\ Sardar Vallabhbhai National Institute of Technology, Surat, Gujarat, India
}

('Corresponding author's e-mail: megha.bhatt.phd@gmail.com)

Received: 8 April 2021, Revised: 8 June 2021, Accepted: 8 July 2021

\begin{abstract}
Diffusion of gaseous and particulate pollutants from tall stacks has formed an important element in the control of air pollution since the industrial revolution began. These tall reinforced concrete chimneys are considered to be cantilever columns subjected to axial load resulted from the self-weight of the shell, linings and other accessories and bending moments which are resulted from the lateral loads like wind forces and earthquake forces.

The recently published IS: 4998 - 2015 adopted a limit state design concept which requires well defined stress-strain relationship for concrete and steel. It has been seen that there are many disparities lies between the stress-strain relationships of constituent materials adopted by IS: $4998-2015$ and other design standards.

This paper discusses various methods pertaining to the estimation of the ultimate strength of thinwalled hollow circular sections of reinforced concrete chimneys, subjected to wind loading. A comparative study of various methods based on the prevalent codes reveals considerable disparity in the predicted ultimate strength values. These differences have been critically analyzed and results are discussed in this paper in terms of ultimate strength along with the contribution of concrete and steel, ultimate curvature and depth of neutral axis. For the comparison of above-mentioned parameters, design recommendations of IS 4998 - 2015, CICIND 2011, ACI 307 - 08 are used.
\end{abstract}

Keywords: RC chimney section, Ultimate moment, IS: 4998 - 2015, CICIND 2011, ACI 307 - 08

\section{Introduction}

As industries are being forced to follow stringent regulations formed by the environmental board; the need for the construction of RC chimneys with a substantial increase in height as an effective means to control the environmental pollution has arisen.

RC chimney used to be considered as a thin-walled hollow circular cantilever column subjected to axial compression mainly due to its self-weight and bending moment due to lateral loads. For the design of chimneys, wind forces are considered as predominant lateral load, which is generally more critical than the seismic forces. The ultimate strength of the RC chimney section is defined as its ultimate moment carrying capacity when it is subjected to an axial compressive load associated with a particular neutral axis depth within the section. Analysis of RC chimney sections as per the above limit state condition requires the specification of appropriate stress-strain relationship for concrete and steel. Different stressstrain relationships have been adopted by various codes for this purpose.

IS: 4998 - 2015 [1] has been revised for the third time and adopted a limit state design approach for the design of $\mathrm{RC}$ chimney sections. Before the code has been revised many researchers have done analytical research work on this subject. Rai et al. [2] plotted the load-moment interaction curves for hollow circular sections utilizing stress-strain curve specified in IS: 456 - 2000 [3] and compared with interaction curves plotted with working stress conditions prescribed in IS: 11628 - 1985 [4] and IS: 4998 - 1975 [5] for cracked section analysis and concluded that limit state method should be adopted for hollow circular sections rather than working stress method. Narayan and Yaragal [6] have developed a computer program to plot the load-moment interaction diagrams and to design the hollow circular section using a simplified rectangular stress block. But neither the stress-strain relationship given in IS: $456-$ 2000 [3] nor the rectangular stress block for concrete can be directly used for the thin-walled hollow circular sections like a chimney. Rao and Menon [7] suggested a new stress-strain relationship for concrete and plotted the load-moment interaction curves and compared the same with interaction curves 
plotted with the provisions of various other well-established codes. The methods selected for the detailed comparison in this paper are IS: 4998 - 2015 [1], CICIND 2011 [8] and ACI 307 - 08 [9].

\section{Research significance}

A comparison of various prevalent design provisions with regards to specified load, strength reduction factors, maximum strain limits for concrete as well as steel, and the criteria for estimating the ultimate strength of hollow circular RC thin-walled sections reveals significant disparities as pointed out in Table 1.

Table 1 Design criteria in different design codes.

\begin{tabular}{|c|c|c|c|c|c|c|c|c|}
\hline \multirow[t]{2}{*}{ Design standards } & \multicolumn{2}{|c|}{$\begin{array}{l}\text { Load factor } \\
\text { for wind }\end{array}$} & \multicolumn{3}{|c|}{ Strength reduction factor } & \multicolumn{2}{|c|}{ Strain limit } & \multirow{2}{*}{$\begin{array}{c}\begin{array}{c}\text { Modulus of } \\
\text { elasticity in } \\
\text { MPa }\end{array} \\
\begin{array}{c}\text { Steel } \\
\text { ' } E_{s},\end{array} \\
\end{array}$} \\
\hline & DL & $\mathbf{W L}^{*}$ & $\begin{array}{c}\text { Concrete } \\
{ }^{\prime} y_{c} \text { ' }\end{array}$ & $\begin{array}{c}\text { Steel } \\
\text { ' } \gamma_{s} \text { ' }\end{array}$ & Overall & $\begin{array}{c}\text { Concrete } \\
\text { ' } \varepsilon_{c, \max } \text { ' }\end{array}$ & $\begin{array}{c}\text { Steel } \\
\text { 'E } \varepsilon_{s, \max },\end{array}$ & \\
\hline IS: $4998-2015$ & $\begin{array}{c}0.9 \\
\text { or } \\
1.2\end{array}$ & 1.6 & 1.5 & 1.15 & - & 0.002 & 0.05 & $2 \times 10^{5}$ \\
\hline CICIND 2011 & 1.0 & 1.6 & 1.5 & 1.15 & - & 0.003 & 0.01 & $2.1 \times 10^{5}$ \\
\hline ACI $307-08$ & $\begin{array}{c}0.9 \\
\text { or } \\
1.2 \\
\end{array}$ & 1.6 & - & - & 0.8 & 0.003 & 0.07 & $2 \times 10^{5}$ \\
\hline
\end{tabular}

*Factor 1.6 shall be used for Along Wind Load

In the light of the above, it is felt that the present study based on the analysis and comparison of some of the already well-established international methods with the method adopted by IS: 4998 - 2015 [1], will considerably enhance the knowledge based on this topic.

The scope of the paper is limited to the analytical study of design methodologies adopted by IS: 4998 - 2015 [1], CICIND 2011 [8] and ACI 307 - 08 [9] and compares the results of the study based on the ultimate moment-resisting capacity of the section including the comparison of the contribution of its constituent materials (concrete and steel), ultimate curvature, and depth of neutral axis.

\section{Stress-strain curve for concrete}

In IS: 4998 - 2015 [1], the compressive stress is assumed to increase parabolically from 0 at 0 strain to peak value as indicated in Figure 1. In comparison with the other 2 codes, IS: 4998 - 2015 [1] specifies the stringent value of concrete strain at failure as 0.002 and introduces the short-term loading factor. This short-term loading effect was distinctively introduced in the 1984 edition of CICIND [10], in which it was assumed that the concrete stress-strain relationship is parabolic under long-term loading and linear under short-term loading with the concrete strain at failure limited to about 0.001 .

This material law of concrete is based on the observations of the experimental research work of Naokowski [11] in which he tested the reinforced concrete specimens under reversed cyclic loading. However, the results of the above experimental work based on reverse cyclic loading do not apply to the typical along wind conditions considered in the CICIND 1984 code [10], as the behaviour of along-wind loading is better approximated by monotonic loading rather than cyclic loading [12] as the along-wind loading and its response is somewhat quasi-static. However, the latest edition of the CICIND Code (2011) [8] ignores this short-term loading effect and considers the parabolic stress-strain behaviour of concrete under permanent loading only with the concrete strain at failure limited to 0.003 at the center of the wall for horizontal chimney sections as shown in Figure 2. 


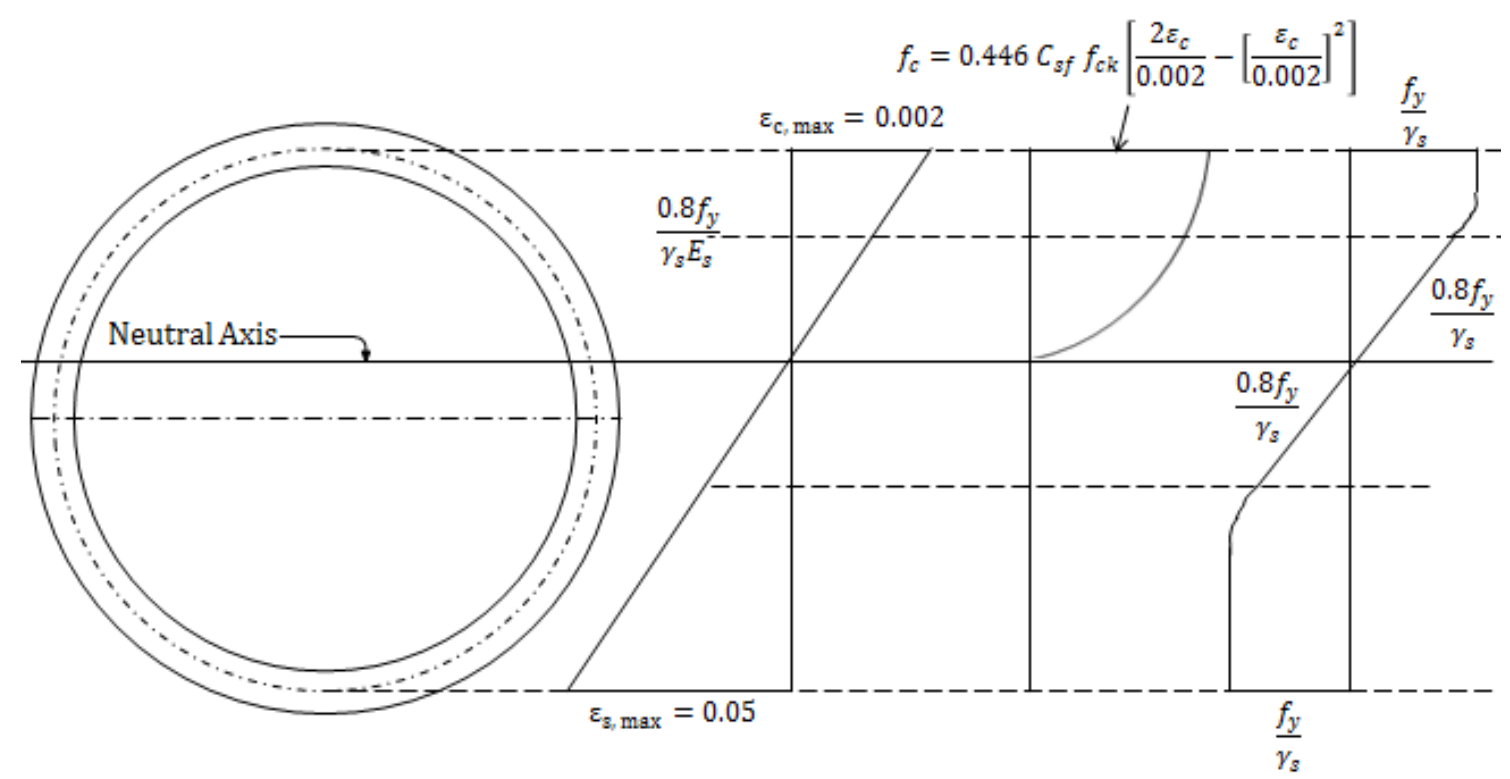

Figure 1 Stress-Strain Law for Cross Section of RC Chimney as per IS: 4998 - 2015.

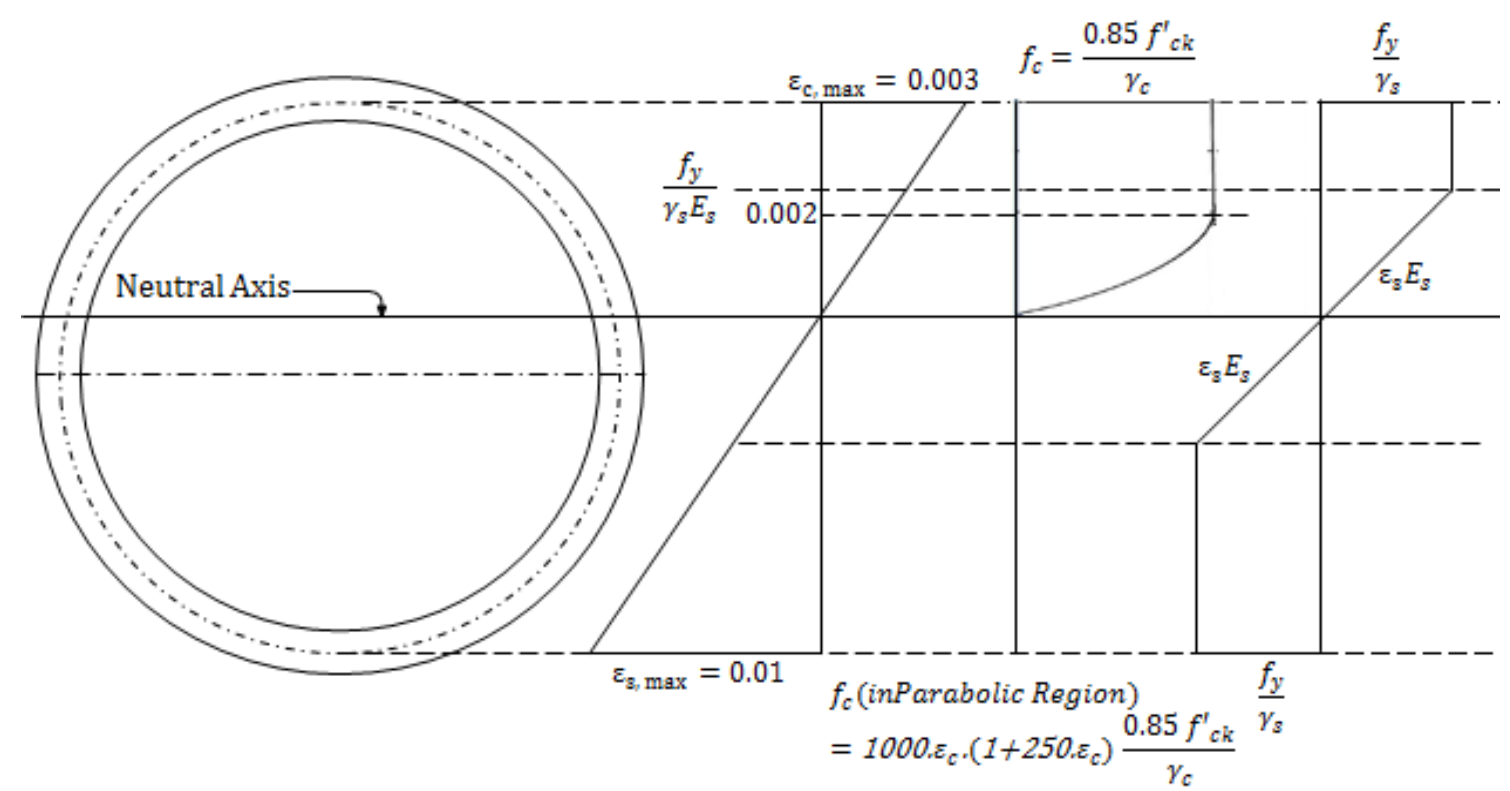

Figure 2 Stress-Strain Law for Cross Section of RC Chimney as per CICIND - 2011.

On the other hand, the latest edition of IS: 4998 - 2015 [1] brings in the short-term wind loading effect by introducing the short-term loading factor ' $C_{s f}$ '. This ' $C_{s f}$ ' factor depends on the axial compression ' $P_{u}$ ' on the chimney section and varies from 1.12 for $P_{u}=0$ and 1 for $P_{u}=P_{u \text {, max }}$ i.e., under pure compression. In the research paper of Rao and Menon [7], which forms the basis of IS: 4998 - 2015 [1] proposal, a logical formwork has been formulated for the concrete stress-strain curve, which accounts for the effects of tubular geometry and short-term loading factor ' $C_{s f}$ '. This ' $C_{s f}$ ' factor in the research paper [7] is obtained using the results of the experimental research work of Rusch [12] and the works of Ellingwood et al. [13]. In the research work [12] of Ruch, a family of stress-strain curves was reported, based on a large number of tests on eccentrically loaded concrete cylinders under varying load durations, which leads towards the conclusion that if the maximum concrete strain is limited to 0.002 then it is reasonable to assume an increase of approximately $10 \%$ for relatively short-term loading. Ellingwood et al. [13] had also suggested a similar strength enhancement factor; under wind loading conditions, in their reliability study of RC columns. Formula given in the code IS: 4998 - 2015 [1] to calculate the ' $C_{s f}$ ' factor is as follows: 
$C_{s f}=\left[0.95-0.1\left(P_{u} / P_{\text {umax }}\right)\right] / 0.85$

Where,

$\mathrm{P}_{\mathrm{u}}=$ Factored axial load and;

$P_{u \max }=2 \pi r t\left[\left(\frac{0.67 f_{c k}}{\gamma_{c}}\right)\left(1-\frac{p_{t}}{100}\right)+f_{s}\left(\varepsilon_{c u}\right)\left(\frac{p_{t}}{100}\right)\right]$

The stringent value of 0.002 for maximum strain in concrete in axial compression with the presence of bending seems to be valid because even in the presence of bending, the strain gradient across the thickness at the extreme compression location is marginal, as the diameter of the chimney is very large in comparison with the thickness of the shell.

However, ACI $307-08$ [9] follows Whitney's rectangular stress block with some modification as shown in Figure 3 assuming the maximum strain in concrete as 0.003 excluding the modification factor ' $Q$ '. Rectangular stress block as per ACI: $318-2002$ [14] is proved to be correct for rectangular and T shaped beams but not for hollow circular reinforced concrete sections like a chimney in which the maximum concrete compressive strain is less than 0.003 when the fracture limit of steel is reached i.e., the compressive stress block is not fully developed. To incorporate these parameters, the modification factor ' $Q$ ' is introduced in the stress block of concrete. This modification factor is however based on the limited experimental work of Morkin and Rumman in 1985 [15] and the numerical study undertaken by the committee.

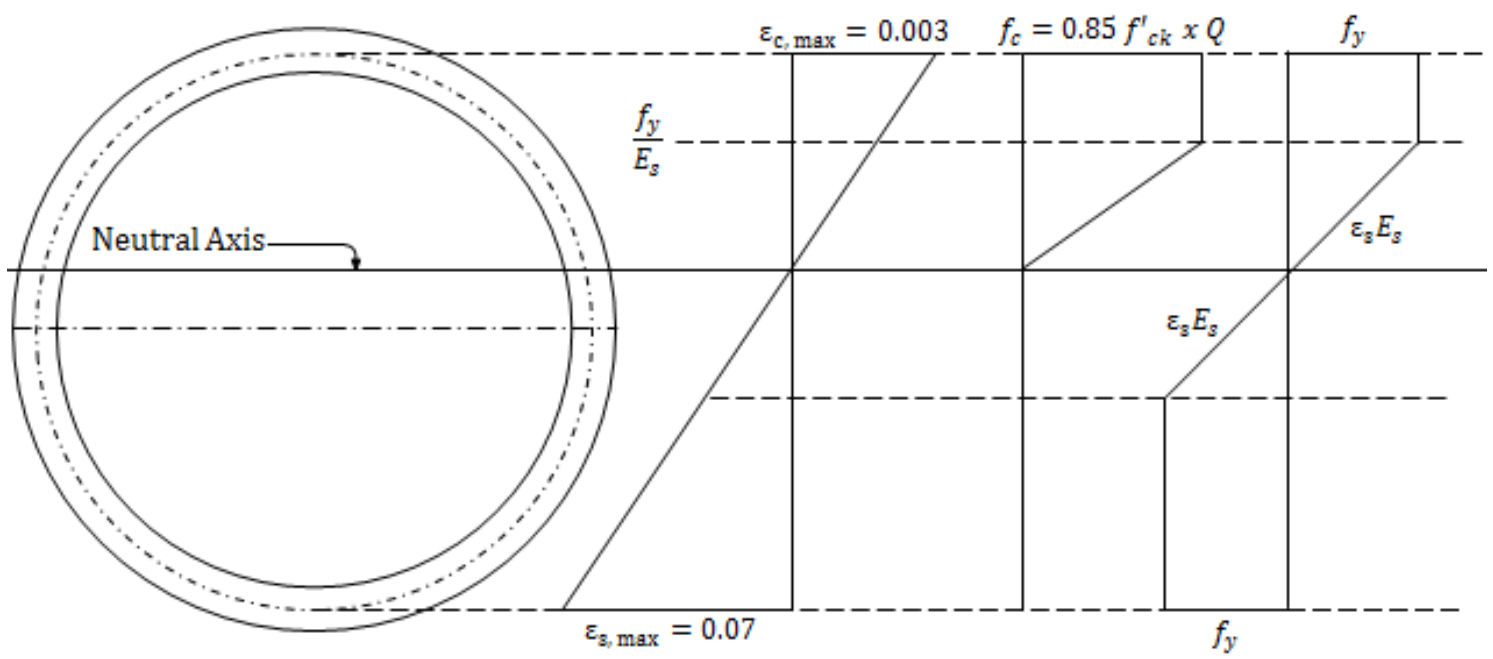

Figure 3 Stress-Strain Law for Cross Section of RC Chimney as per ACI $307-08$.

The peak stress in concrete in the compressive zone ' $f_{c}$ ' is specified in terms of characteristic cube strength ' $f_{c k}$ ' in IS: $4998-2015$ [1] and in terms of characteristic cylindrical strength ' $f$ ' $c k$ ' in CICIND $2011[8]$ and ACI $307-08$ [9], where $f_{c k}^{\prime}=0.8 f_{c k}$.

\section{Stress-strain curve for steel}

ACI $307-08$ [9] and CICIND 2011 [8] adopted the idealized elasto-plastic stress-strain relationship for steel in tension and compression assuming that reinforcement exhibits sharp yielding behavior. IS: 4998 - 2015 [1] on the other hand, has embraced an alternative approach for determining the yield strength known as the offset approach for the design process. In this method, the characteristic strength is taken as that stress at which the material shows specified limiting deviation from stress-strain proportionality, the value of which is conventionally taken as $0.2 \%$ of proof stress. After comparing the ultimate strength of RC beams and columns using different stress-strain relations of steel i.e., with the sharp yield plateau and gradually yielding curves wherein the yield strengths are obtained using offset 
values of 0.1 and $0.2 \%$, Paulson et al. [16] concluded that the $0.2 \%$ offset approach used to determine the yield strength of gradually yielding reinforcing steel is safe and practical. The other differences between the 3 methods are with regards to the specifications of modulus of elasticity of steel ' $E_{s}$ ' and limiting tensile strain in steel ' $\varepsilon_{s, \text { max }}$ ', which can be seen from Table 1.

\section{Formulation of spreadsheet program}

The ultimate moment capacity ' $M_{u}$ ' is the moment when the strain in concrete reaches its maximum value. The ' $M_{u}$ ' corresponding to any given normal compression is determined by solving the following equilibrium equations:

$P_{u}=P_{u c}+P_{u s}$

$M_{u}=M_{u c}+M_{u s}$

Where ' $P_{u c}$ ' and ' $P_{u s}$ ' are the resultant ultimate forces obtained from concrete and steel stress blocks, and ' $M_{u c}$ ' and ' $M_{u s}$ ' denote the moments about the centerline of that tubular section as explained below:

$P_{u c}=f_{c} x A_{c}$ and $M_{u c}=P_{u c} x X_{c}$

Where,

$X_{c}=$ Distance between the CG of the strip and CG of the Section

$A_{c}=$ Area of concrete of the strip

$f_{c}$ as per IS: $4998-2015$ [1]

$$
f c=\frac{0.67 C_{s f} f_{c k}}{1.5}\left\{2\left(\frac{\varepsilon_{c}}{0.002}\right)-\left(\frac{\varepsilon_{c}}{0.002}\right)^{2}\right\}
$$

Where,

$C_{s f}=\left[0.95-0.1\left(P_{u} / P_{\text {umax }}\right)\right] / 0.85$

Where,

$\mathrm{P}_{\mathrm{u}}=$ Factored axial load and

$$
P_{u \max }=2 \pi r t\left[\left(\frac{0.67 f_{c k}}{\gamma_{c}}\right)\left(1-\frac{p_{t}}{100}\right)+f_{s}\left(\varepsilon_{c u}\right)\left(\frac{p_{t}}{100}\right)\right]
$$

$f_{c}$ as per CICIND 2011 [8]

$$
\begin{aligned}
& \text { For } \varepsilon_{c} \leq 0, \quad f_{c}=0 \\
& -0.002 \leq \varepsilon_{c}<0, \quad f_{c}=1000 . \varepsilon_{c} .\left(1+250 \varepsilon_{c}\right) .\left(0.85 f^{\prime}{ }_{c k}^{\prime} / 1.5\right) \\
& -0.003 \leq \varepsilon_{c}<-0.002, \quad f_{c}=-\left(0.85 f^{\prime}{ }_{c k} / 1.5\right)
\end{aligned}
$$

$f_{c}$ as per ACI $307-08$ [9]

$f_{c}=0.85 f^{\prime}{ }_{c k} \times Q$

Where, $Q$ can be derived by the following equations, where $\alpha$ is the on chimney cross section, one-half of the central angle subtended by neutral axis, radians

For $\alpha \leq 5$ degrees

$Q=\left(-0.523+0.181 \alpha-0.0154 \alpha^{2}\right)+\left(41.3-13.2 \alpha+1.32 \alpha^{2}\right)(\mathrm{t} / \mathrm{r})$

For 5 degrees $<\alpha \leq 10$ degrees

$\mathrm{Q}=\left(-0.154+0.01773 \alpha+0.00249 \alpha^{2}\right)+\left(16.42-1.980 \alpha+0.0674 \alpha^{2}\right)(\mathrm{t} / \mathrm{r})$

For 10 degrees $<\alpha \leq 17$ degrees

$\mathrm{Q}=(-0.488+0.076 \alpha)+(9.758-0.640 \alpha)(\mathrm{t} / \mathrm{r})$

For 17 degrees $<\alpha \leq 25$ degrees

$\mathrm{Q}=\left(-1.345+0.2018 \alpha+0.004434 \alpha^{2}\right)+\left(15.83-1.676 \alpha+0.03994 \alpha^{2}\right)(\mathrm{t} / \mathrm{r})$

For 25 degrees $<\alpha \leq 35$ degrees

$\mathrm{Q}=(0.993-0.00258 \alpha)+(-3.27+0.0862 \alpha)(\mathrm{t} / \mathrm{r})$

For $\alpha>35$ degrees

$\mathrm{Q}=0.89$

$P_{u s}=f_{s} \times A_{s}$ and $M_{u c}=P_{u s} \times X_{s}$

Where,

$X_{s}=$ Distance between the CG of the reinforcement and CG of the Section 
$f_{s}$ is the stress in the steel can be obtained by stress-strain relationship of steel as mentioned in different codes and are as shown in Figures 1-3.

$A_{s}=$ is the area of steel at that layer

A standard chimney cross-section consisting of outer diameter $10 \mathrm{~m}$, thickness $0.45 \mathrm{~m}$, concrete strength $f_{c k}=40 \mathrm{MPa}$ and reinforcement yield strength $f_{y}=500 \mathrm{MPa}$ are used in this study together with the percentage of reinforcement as $p_{t}=0.3,0.5,0.75,1.0,1.5$ and $2.0 \%$ and axial stress ratio $n=0$ to 0.2 at increments of 0.025 . Where ' $f_{c}$ ' is the axial stress generated due to the axial force on the section.

A generalized computer program is developed to determine the ultimate characteristics of the hollow circular thin-walled reinforced concrete section. The program requires the input of material and geometrical properties of the section and the axial force which is input indirectly by optimizing the neutral axis depth. The neutral axis location for the ultimate condition is optimized using the 'Goal Seek' function to obtain the specified design axial force acting on the section.

The entire cross-section is divided into the number of small strips parallel to the neutral axis. To maintain the accuracy of the program, the width of each strip is maintained as $1 \mathrm{~mm}$. The strain at the centroid of each strip is calculated assuming that the plane section remains plane. Individual concrete and steel stresses are calculated from the one-dimensional constitutive stress-strain relationship. The net stress acting at the centroid of each strip is then multiplied by the concrete area of that strip to obtain the ultimate force shared by the concrete and a similar method is adopted to calculate the ultimate force shared by the steel. These forces and the product of the forces with the centroidal distances are summed to obtain the resultant axial force and bending moment values for a given neutral axis position.

\section{Results and discussion}

The results of the comparative study between the 3 design codes, carried out on reinforced concrete chimney sections for the percentage of reinforcement $p_{t}=0.3,0.5,0.75,1.0,1.5$ and $2.0 \%$ and axial stress ratio $n=0$ to 0.2 are discussed in this section in terms of ultimate moments along with the contribution of its constituent materials namely concrete and steel, ultimate curvatures and depth of neutral axis.

\section{Comparison of ultimate moments}

The ultimate moment capacity ' $M_{u}$ ' of the section calculated for 3 design methods are compared in this section along with the comparison of the contribution of the constituent materials namely concrete and steel.

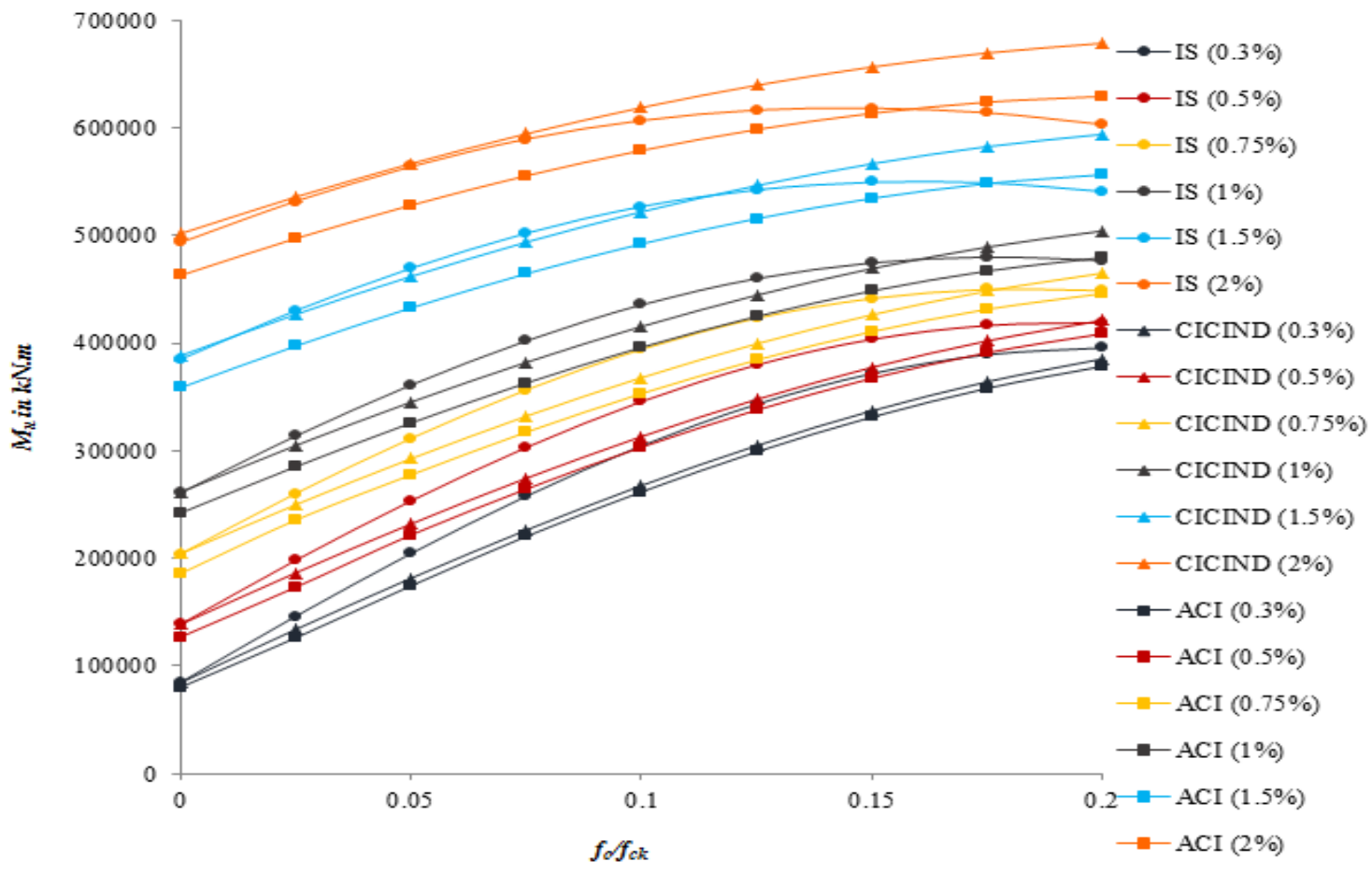

Figure 4 Comparisons of ultimate moments. 
The salient observations from the above graphs are listed below:

1. The disparities among the various methods are small when ' $n$ ' is low and the reinforcement ratio is minimum. However, they become increasingly pronounced with an increase in $\mathrm{n}$ and tend to be very large at high reinforcement ratios. When the axial stress ratio ' $n$ ' is low and the section is lightly reinforced, extreme tension condition prevails, wherein the concrete stress-strain curve has hardly any contribution to make. However, as ' $n$ ' increases, the section is subjected to more of compression, and hence the difference between the various methods gets emphasized. Figure 8 compares the values of the depth of neutral axis ' $X_{u}$ ' also confirms the above statement.

2. Figure 4 also indicates an increase in moment strength with an increase in axial load and reinforcement ratio for 'ACI' and 'CICIND', but on the other hand at higher ratios, it can be observed that the ultimate strength obtained from 'IS' which is highest amongst the 3 codes up to lower stress ratio, has substantially reduced non-linearly and falls below the values obtained from 'ACI' and 'CICIND'; this reduction is significant for higher steel ratios i.e., for 1.5 and $2 \%$. To understand the difference between values of the ultimate moment contribution of concrete and steel, the graphs are separately plotted.

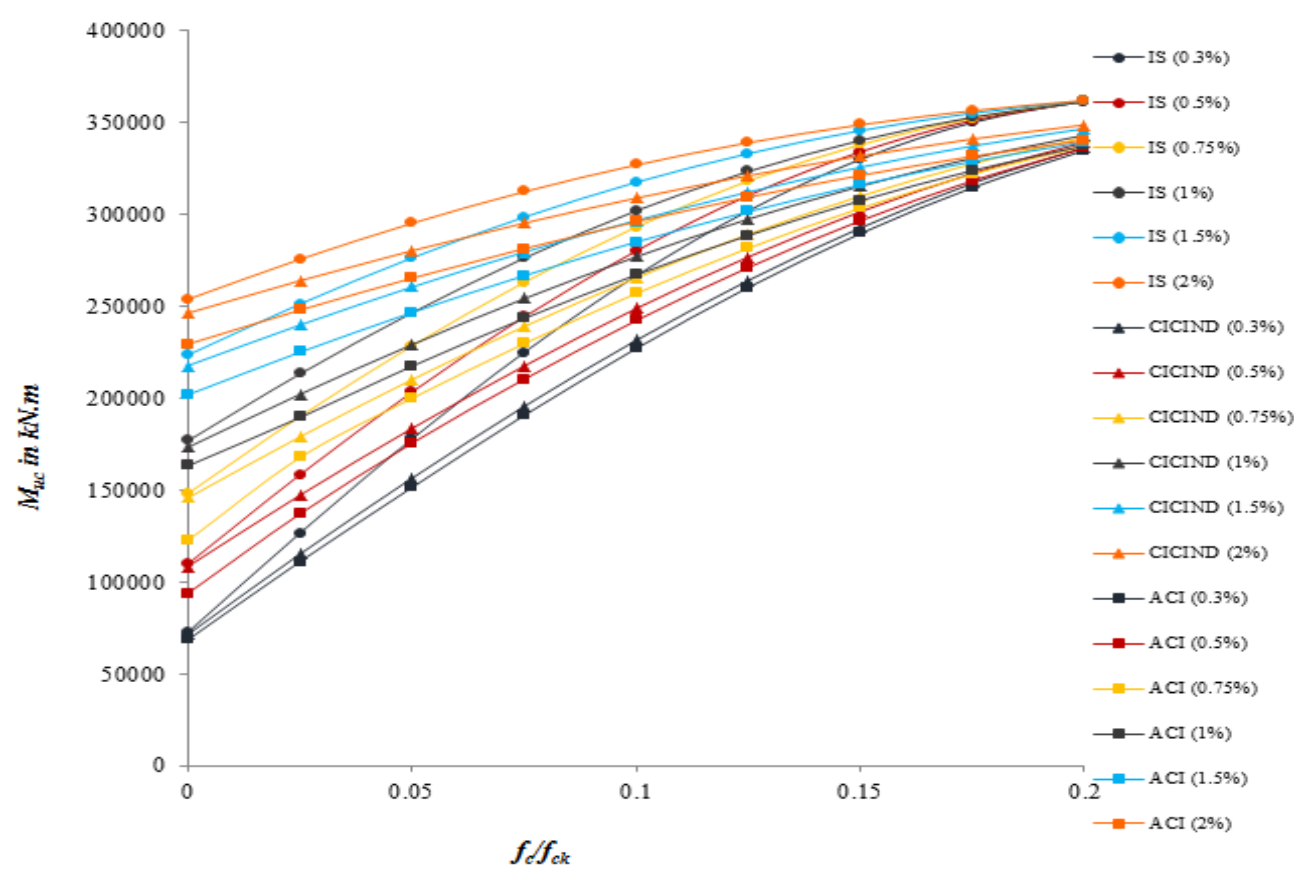

Figure 5 Comparisons of the contribution of concrete in ultimate moments.

It can be seen from Figure 5, that the share of ultimate capacity of concrete increases with an increase in stress ratio for all 3 methods. However, it can be observed that the share of concrete calculated using the 'IS' methodologies is higher than the share of concrete obtained from the 'ACI' and 'CICIND' methodologies. This increment in the share of concrete obtained using 'IS' stress-strain relationship is more significant at a higher stress ratio and a lower percentage of steel.

It is also observed from Figure 6 that at a higher stress ratio, the contribution of steel in ultimate moment capacity is reduced when calculated using 'IS' methodology as compared to the methodologies using other 2 codes and hence, this decrement creates a difference in the results of Indian design code with the other design codes. Also, this difference further increases with an increase in the percentage of steel. 


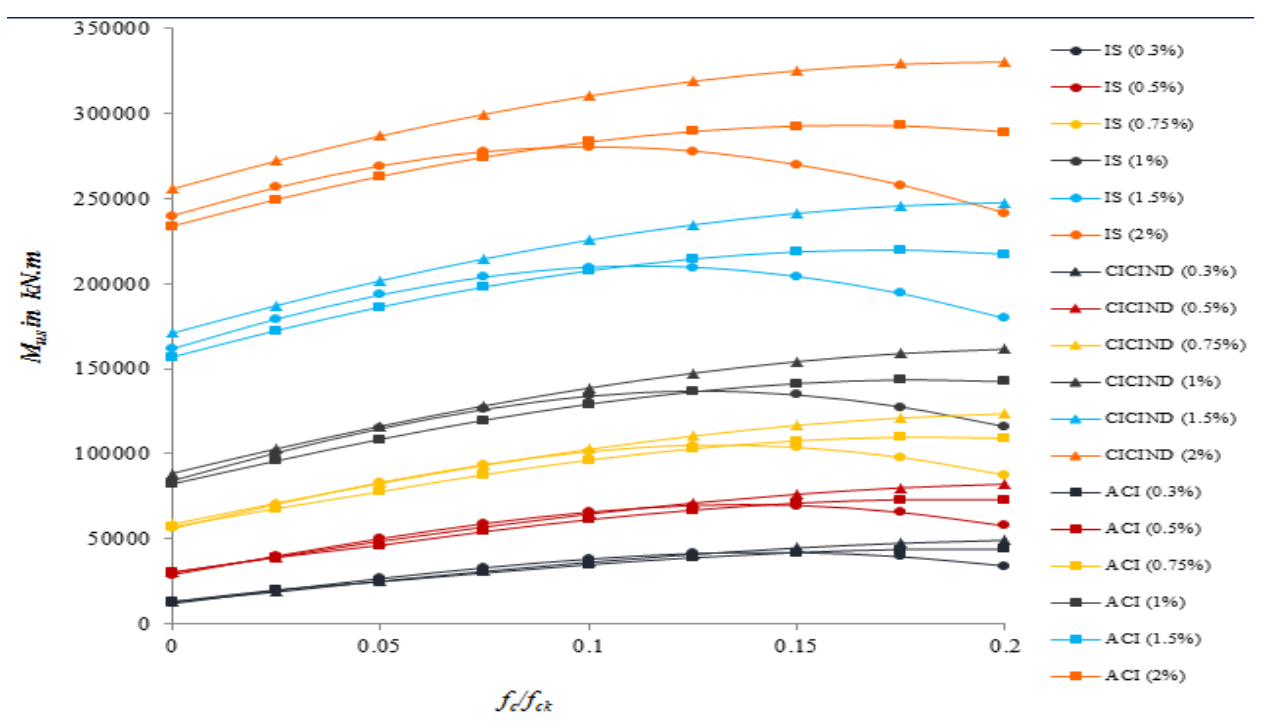

Figure 6 Comparisons of the contribution of steel in ultimate moments.

From Figures 4 - 6, it can be concluded that at a lower percentage of steel and up to stress ratio of 0.15 , the values of ' $M_{u}$ ' is higher for 'IS' compared to 'ACI' and 'CICIND' as the share of concrete is higher in that range.

Beyond the stress ratio of 0.15 the reduction in ' $M_{u}$ ' calculated from 'IS' is mainly due to the reduction in the contribution of steel in ' $M_{u}$ ' which is significant at a high percentage of steel, as the share of concrete is still increasing but this share is having only a marginal increase in comparison with 'ACI' and 'CICIND' at a higher percentage of steel.

\section{Comparison of ultimate curvatures}

The ultimate curvature ' $\phi_{u}$ ' is calculated by dividing the nominal ultimate concrete strain by the depth of the neutral axis. The results plotted in Figure 7 indicate the reduction in curvature capacity as the axial stress ratio or the reinforcement ratio increases. The comparison indicated a reasonable correlation although the 'IS' design methodologies slightly underestimated the ultimate curvature values. The differences could be attributed to the neutral axis depth being greater for 'IS'. The differences can be expected to be greater when the axial load and neutral axis depths increase.

\section{Comparison of depth of neutral axis}

The neutral axis depth measured from the centerline of the reinforced concrete chimney section associated with the ultimate moment is calculated using the generalized computer program. The neutral axis depth increases with an increase in the axial stress ratio and percentage of steel. It varies from 141 to $1,629 \mathrm{~mm}$ for $0.3 \%$ reinforcement and 5,339 to $5,010 \mathrm{~mm}$ for $2 \%$ of reinforcement. It can also be seen that differences between the 3 codes are almost negligible at 0 stress ratio and increases at higher stress ratio. 


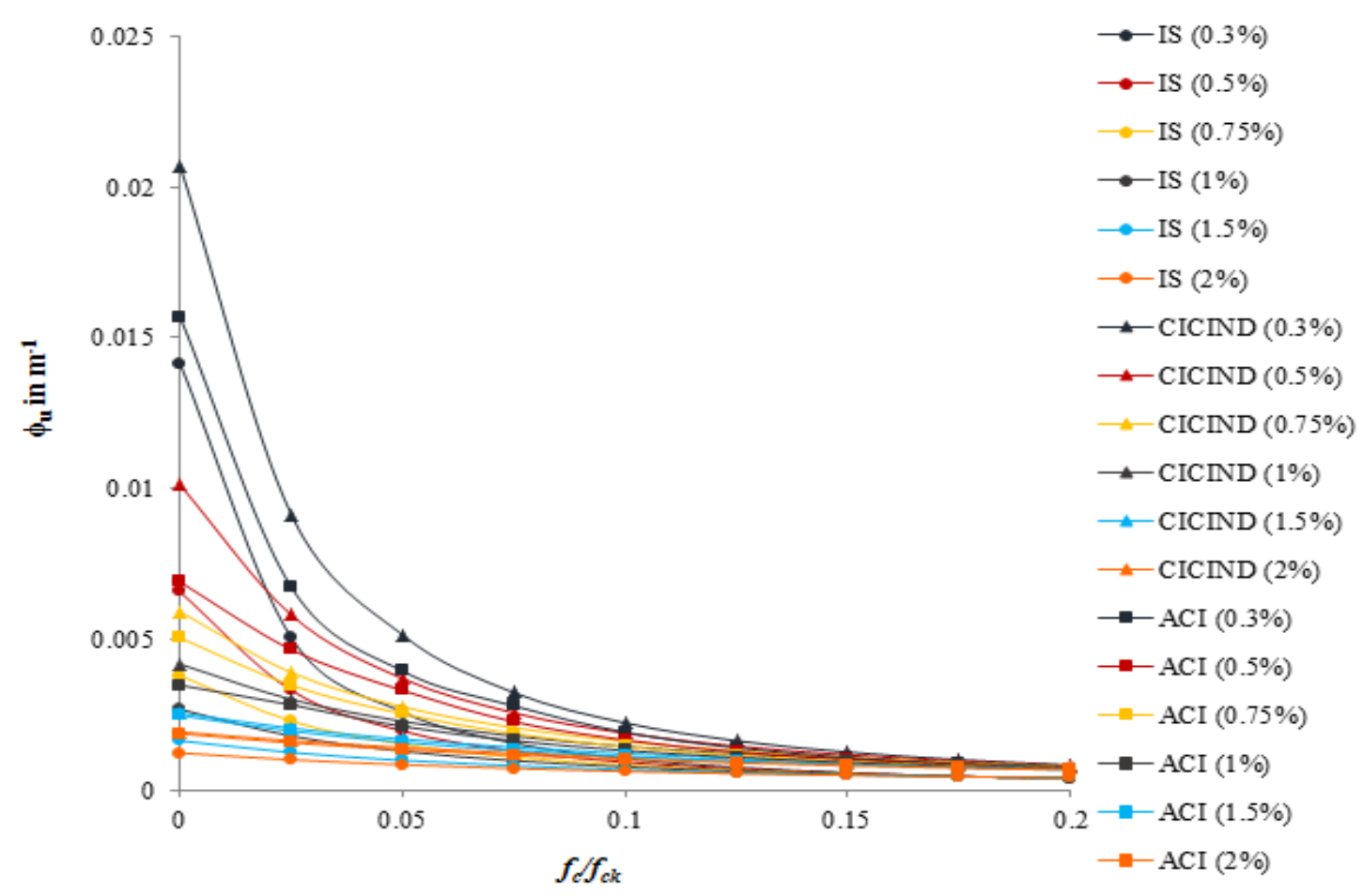

Figure 7 Comparison of ultimate curvature.

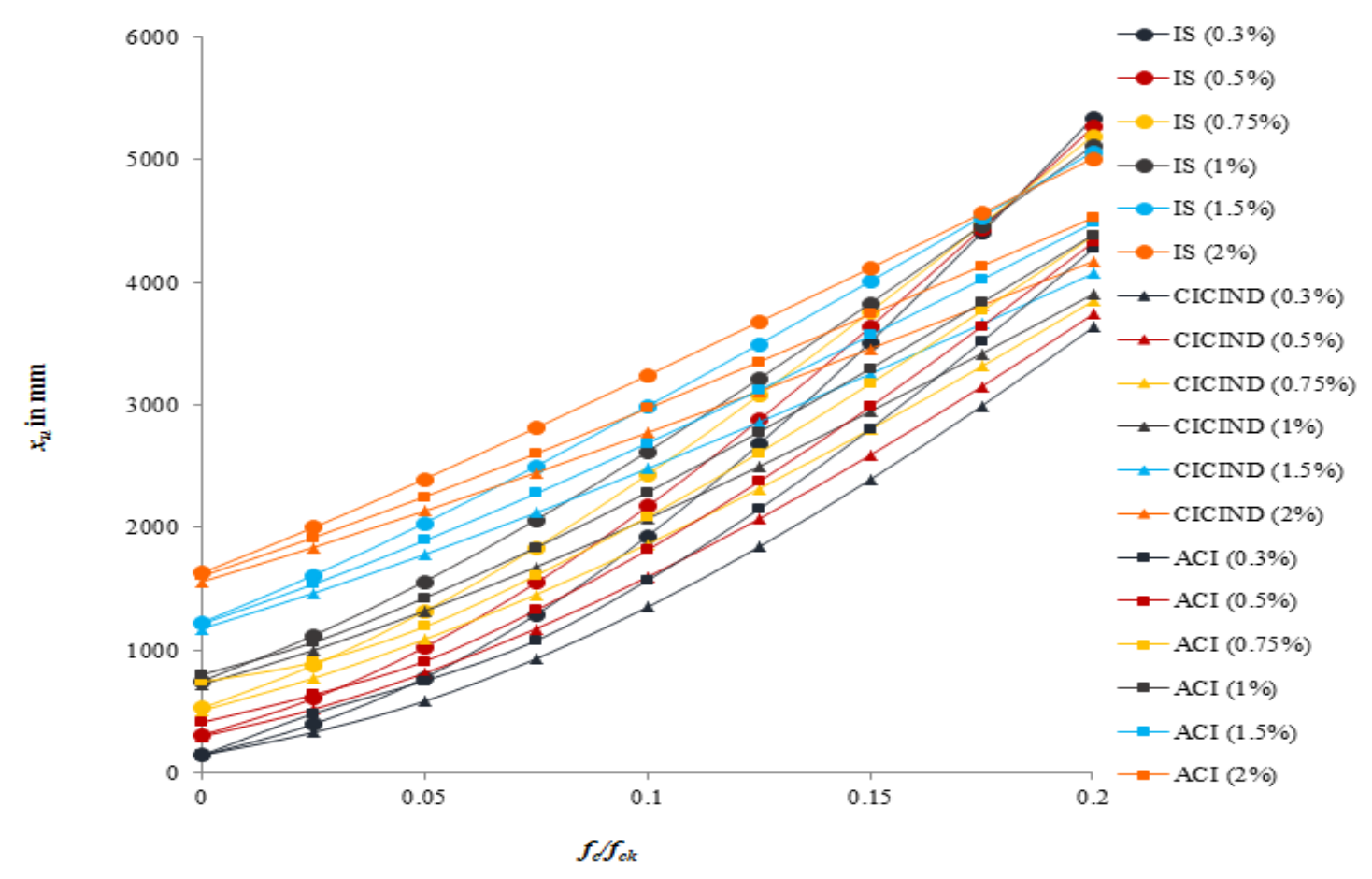

Figure 8 Comparisons of the depth of neutral axis. 


\section{Conclusions}

Analytical strengths of hollow thin-walled tubular reinforced concrete chimney sections incorporating the stress-strain models of concrete and steel given in IS: 4998 - 2015, ACI $307-08$ and CICIND 2011 are compared.

There exist considerable differences between the above 3 prevailing methods to estimate the ultimate moment capacity of the tubular reinforced concrete section, subject to wind moment combined with normal compressive dead load. These disparities are predominant at higher stress ratio and high steel ratio. These disparities are due to differences in the various stress-strain models of concrete at a lower percentage of steel i.e., up to $0.75 \%$ and at lower stress ratio i.e., up to 0.125 ; but at a higher percentage of steel i.e., from 1 to $2 \%$, these disparities are due to the difference in stress-strain models of steel adopted by the 3 codes.

The strain specified in the distribution as per 'ACI' and 'CICIND' (0.003) methods are larger than those specified by the 'IS' method (0.002); hence the corresponding steel stresses are also larger, both in compression and tension. But this is offset by the descending branch of the concrete stress-strain curve of 'ACI' method, which results in a smaller concrete stress block area. At lower values of steel percentage, this influence of concrete is overriding; also, at higher values of steel percentage, the increased influence of steel results in 'ACI' and 'CICIND' predicting larger strengths than 'IS', as in 'IS,' none of the steel in the tension zone reaches the yield strength whereas, in the 'ACI' and 'CICIND', most of the steel in the tension zone acquires the full yield strength.

\section{Acknowledgements}

I owe my gratitude to the Head and Professor of Civil Engineering Department Dr. M. Mansoor Ahammed, SVNIT, Surat for his moral support and co-operation. I also thank to all the faculties of Civil Engineering Department, SVNIT, Surat. I feel privileged in expressing my profound sense of gratitude to Mr. Rakesh Shah, S3M Design Consultants LLP, Ahmedabad.

\section{References}

[1] IS: 4998 - 2015. Indian standard code of practice for design of reinforced concrete chimneys: Design criteria. $3^{\text {rd }}$ eds. Bureau of Indian Standards, New Delhi, India, 2015.

[2] DC Rai, K Kumar and HB Kaushik. Ultimate flexural strength of reinforced concrete circular hollow sections. Indian Concr. J. 2006; 80, 39-45.

[3] IS: 456 - 2000. Indian standard code of practice for plain and reinforced concrete for general building construction. Bureau of Indian Standards, New Delhi, India, 2000.

[4] IS: 11628 - 1985. Criteria for design of RCC staging for overhead water tanks. Bureau of Indian Standards, New Delhi, India, 1985.

[5] IS: 4998 - 1975. Indian standard code of practice for design of reinforced concrete chimneys: part 1: Design criteria. $1^{\text {st }}$ Rev. Bureau of Indian Standards, New Delhi, India, 1975.

[6] KSB Narayan and SC Yaragal. Load-moment interaction envelops for design of tall stacks: A limit state approach. Indian Concr. J. 2007; 81, 21-5.

[7] PS Rao and D Menon. Ultimate strength of tubular RC tower sections under wind loading. Indian Concr. J. 1995; 69, 117-23.

[8] CICIND. Model code for concrete chimneys - part A: the shell. $3^{\text {rd }}$ eds. International Committee for Industrial Construction, Germany, 2011.

[9] ACI 307. Code requirements for reinforced concrete chimneys (ACI 307-08) and commentary. American Concrete Institute, Michigan, 2008.

[10] CICIND. Model code for concrete chimneys - part A: the shell. $2^{\text {nd }}$ eds. Comite International Des Chimness Industrielle, Zurich, Switzerland, 1984.

[11] P Naokowski. The behaviour of the compressed zone of concrete industrial chimney. In: Proceedings of the $4^{\text {th }}$ International Symposium on Industrial Chimneys, The Hauge, Netherlands. 1981.

[12] H Rusch. Researches toward a general flexural theory for structural concrete. J. Am. Concr. Inst. 1960; 57, 1-28.

[13] B Ellingwood, TV Galambos, JC MacGregor and CA Cornell. Development of a probability based load criterion for American national standard A58. National Bureau of Standards, Washington DC, 1980.

[14] ACI Committee 318. Building code requirements for reinforced concrete. American Concrete Institute, Michigan, 2002. 
[15] ZAR Morkin and WS Rumman. Ultimate capacity of reinforced concrete members of hollow circular sections subjected on monotonic and cyclic bending. J. Am. Concr. Inst. 1985; 82, 653-6.

[16] C Paulson, JM Rautenberg, SK Graham and D Darwin. Defining yield strength for non-prestressed reinforcing steel. ACI Struct. J. 2016; 113, 169-78.

[17] Gl Schueller and CG Bucher. On the failure mechanisms of reinforced concrete chimneys. CICIND Report. 1997; 13, 6-10. 